\title{
PERAN KINERJA LABA DALAM MEMODERASI PENGARUH ANTARA CORPORATE SOCIAL RESPONSIBILITY TERHADAP PENGHINDARAN PAJAK
}

\author{
ADHITYA PUTRI PRATIWI ${ }^{1}$, ANI KUSUMANINGSIH ${ }^{2}$ \\ Prodi Akuntansi S1, Fakultas Ekonomi, Universitas Pamulang \\ adhitya.putripratiwi@gmail.com
}

\begin{abstract}
This research aims to determine the role of earnings performance in moderating the influence of Corporate Social Responsibility to Tax Avoidance. The research methode used was the Analytical Causal Associative with a sample size of 31 mining sector companies listed on Indonesia Stock Exchange in 2015-2018. Data collected in this research are secondary data using non-participant observation with the analysis tool E-views 9. Based on the results of the reasearch, it was found that Corporate Social Responsibility affects tax avoidance and earning performance is able to strengthen the influence beetwen Corporate Social Responsibility On Tax Avoidance.
\end{abstract}

Keywords : Corporate Social Responsibility, Profit Performance, Tax Avoidance

\section{PENDAHULUAN}

Pemungutan pajak dimaksudkan guna kemandirian bangsa dari segi finansial, pajak juga digunakan bagi sebesar-besarnya kemakmuran rakyat. Selain hal tersebut, Direktorat Jenderal Pajak juga memandang bahwa kemajuan perekonomian nasional harus ditunjang dengan pembangunan infrastruktur yang membutuhkan dana besar dan pajaklah yang menjadi solusi utama. Namun pada sisi wajib pajak dalam hal ini adalah korporasi yang memiliki tujuan menghasilkan keuntungan dari setiap kegiatan bisnis yang dilakukan, pajak menjadi salah satu hal yang dianggap sebagai penghambat tujuan tersebut dikarenakan pembayaran pajak akan mengambil dari sebagian biaya operasional perusahaan. Perbedaan tujuan antara pemerintah dan perusahaan inilah yang kemudian menimbulkan suatu cara untuk meminimalisir bahkan menghindari pembayaran pajak. Menyimpulkan dengan apa yang terjadi, penulis berasumsi bahwa Tata Kelola Perusahaan menjadi sesuatu yang sangat penting untuk meminimalisir tingkat penghindaran pajak. Salah satu aspeknya adalah Corporate Social Responsibility.

Pelaksanaan Corporate Social Responsibility yang diatur pada Undang-Undang No 40 tahun 2007 tentang Perseroan Terbatas sempat menuai polemik di kalangan pengusaha. Kegiatan CSR yang semula bersifat sukarela, saat ini menjadi sebuah 
kewajiban yang harus dijalankan oleh perusahaan. Berdasarkan Pasal 1 angka 3 Undang-Undang No 40 Tahun 2007 tentang Perseroan Terbatas, Corporate Social Responsibility merupakan komitmen perusahaan untuk berperan serta dalam pembangunan ekonomi berkelanjutan guna meningkatkan kualitas kehidupan dan lingkungan yang bermanfaat, baik bagi perseroan sendiri, komunitas setempat maupun masyarakat pada umumnya. Corporate Social Responsibility dalam pelaksanaannya memerlukan biaya yang tidak bisa dibilang kecil, sedangkan tujuan perusahaan adalah untuk memperkecil biaya operasional demi profit yang besar. Mengutip hasil penelitian PIRAC (2011), Edi Suharto menunjukkan bahwa dan CSR Indonesia mencapai lebih dari 115 miliyar Rupiah atau sekitar 11,5 juta dollar AS dari 180 perusahaan dibelanjakan untuk 279 kegiatan sosial yang terekam oleh media masa. Meskipun dana ini masih sangat kecil jika dibandingkan dengan dana CSR Amerika Serikat Berikut ini merupakan gambaran besarnya biaya CSR yang harus dikeluarkan oleh sebuah perusahaan dalam tiga tahun terakhir :

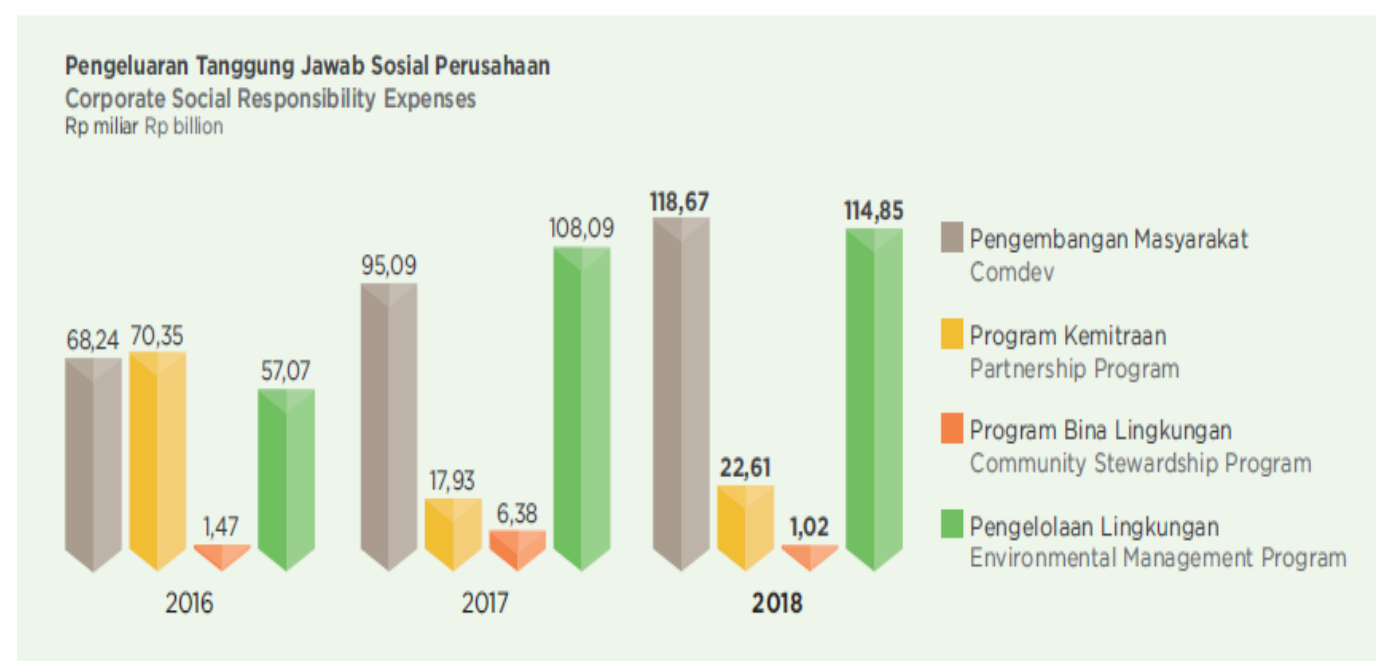

Sumber : Annual Report PT Antam, Tbk, diolah 2019

Gambar 1 : Pengeluaran Tanggung Jawab Social PT Antam, Tbk Tahun 2016-2018

Jika dilihat pada gambar 1.1, tidak dapat dipungkiri bahwa pelaksanaan CSR memerlukan biaya yang cukup besar dalam praktiknya. Oleh karena itu, dapat ditarik kesimpulan bahwa praktik penghindaran pajak dan penyelenggaraan CSR juga dipengaruhi oleh dana yang tersedia pada suatu perusahaan serta sumber daya yang dimilikinya. Bila kinerja laba pada suatu tahun tidak optimal, maka manajemen perlu melakukan alokasi antara pelaksanaan CSR atau pembayaran pajak, pada saat inilah biasanya terjadi sebuah praktik penghindaran pajak. 


\section{METODE RISET}

\section{Tekhnik Pengumpulan Data}

Metode pengumpulan data yang dilakukan dalam penelitian ini adalah studi pustaka, di mana penulis mengumpulkan bahan atau data-data yang ada kaitannya dengan objek penelitian melalui penelaahan terhadap buku-buku, jurnal-jurnal serta analisa yang dapat digunakan dalam penelitian.

\section{ANALISIS DAN PEMBAHASAN}

\section{Analisis Statistik Deskriptif}

Statistik deskriptif digunakan sebagai teknik analisis dengan tujuan untuk menjelaskan atau memberikan gambaran mengenai variabel-variabel dalam penelitian.

Tabel 1. Analisis Statistik Deskriptif

\begin{tabular}{|l|r|r|r|}
\hline & X1 & Y & \multicolumn{1}{l|}{ Z } \\
\hline Mean & 0.225 & 0.389 & 0.095 \\
\hline Median & 0.208 & 0.280 & 0.052 \\
\hline Max & 0.681 & 4.527 & 1.000 \\
\hline Min & 0.021 & 0.000 & 0.000 \\
\hline Std. Dev. & 0.149 & 0.526 & 0.137 \\
\hline Skewnes & 0.754 & 5.769 & 3.738 \\
\hline Kurtosis & 2.987 & 4.157 & 2.135 \\
\hline Jarque-Bera & 1.177 & 8.375 & 2.030 \\
\hline Prob & 0.002 & 0.000 & 0.000 \\
\hline Sum & 2.795 & 4.825 & 1.190 \\
\hline Sum Sq. Dev. & 2.764 & 3.41 & 2.334 \\
\hline Obs & 124 & 124 & 124 \\
\hline
\end{tabular}

Sumber : Hasil olah data Eviews 9, 2019

\section{Pengujian Model Regresi Data Panel}

Estimasi model regresi data panel bertujuan untuk memprediksi parameter model regresi yaitu nilai intersep atau konstanta dan slope atau koefisien regresi. Penggunaan data panel dalam regresi akan menghasilkan intersep dan slope yang berbeda pada setiap perusahaan dan setiap periode waktu. Pemilihan metode pengujian data panel dilakukan pada seluruh data sample (31 perusahaan). Uji chow akan dilakukan pertama kali untuk memilih metode pengujian data panel antara metode common effect atau fixed effect. Jika nilai $\mathrm{F}$ statistik pada uji chow signifikan, maka uji hausman akan dilakukan untuk memilih antara metode fixed effect atau random effect. Hasil uji hausman dengan nilai probabilita kurang dari tingkat signifikansi, maka metode fixed effect yang dipilih untuk menguji data panel. Pemilihan metode pengujian dilakukan dengan menggunakan pilihan fixed effect atau random effect. 


\section{Uji Chow}

Redundant Fixed Effects Tests

Equation: Untitled

Test cross-section fixed effects

\begin{tabular}{lrrr}
\hline \hline Effects Test & Statistic & d.f. & Prob. \\
\hline \hline Cross-section F & 1.340503 & $(30,92)$ & 0.1457 \\
Cross-section Chi-square & 44.967531 & 30 & 0.0389 \\
\hline \hline
\end{tabular}

Cross-section fixed effects test equation:

Dependent Variable: $Y$

Method: Panel Least Squares

Date: 07/15/19 Time: 21:30

Sample: 20152018

Periods included: 4

Cross-sections included: 31

Total panel (balanced) observations: 124

\begin{tabular}{lrlrr}
\hline \hline \multicolumn{1}{c}{ Variable } & Coefficient & Std. Error & t-Statistic & Prob. \\
\hline \hline \multicolumn{1}{c}{ X1 } & -0.277718 & 0.317125 & -0.875737 & 0.3829 \\
\multicolumn{1}{c}{ C } & 0.451792 & 0.085756 & 5.268354 & 0.0000 \\
\hline \hline & 0.006247 & Mean dependent var & 0.389180 \\
R-squared & -0.001899 & S.D. dependent var & 0.526802 \\
Adjusted R-squared & 0.527302 & Akaike info criterion & 1.573909 \\
S.E. of regression & 33.92173 & Schwarz criterion & 1.619398 \\
Sum squared resid & -95.58238 & Hannan-Quinn criter. & 1.592388 \\
Log likelihood & 0.766916 & Durbin-Watson stat & 2.127325 \\
F-statistic & 0.382894 & & & \\
Prob(F-statistic) & & &
\end{tabular}

Sumber : Hasil olah data e-views 9, 2019

Berdasarkan tabel 4.2, didapatkan hasil bahwa nilai probability $\mathrm{F}$ adalah sebesar $0.1457>0.05$, maka terima $\mathrm{H}_{0}$ sehingga pengujian dilakukan menggunakan Random Effect. 


\section{Uji Hausman}

\section{Tabel 4. Uji Hausman}

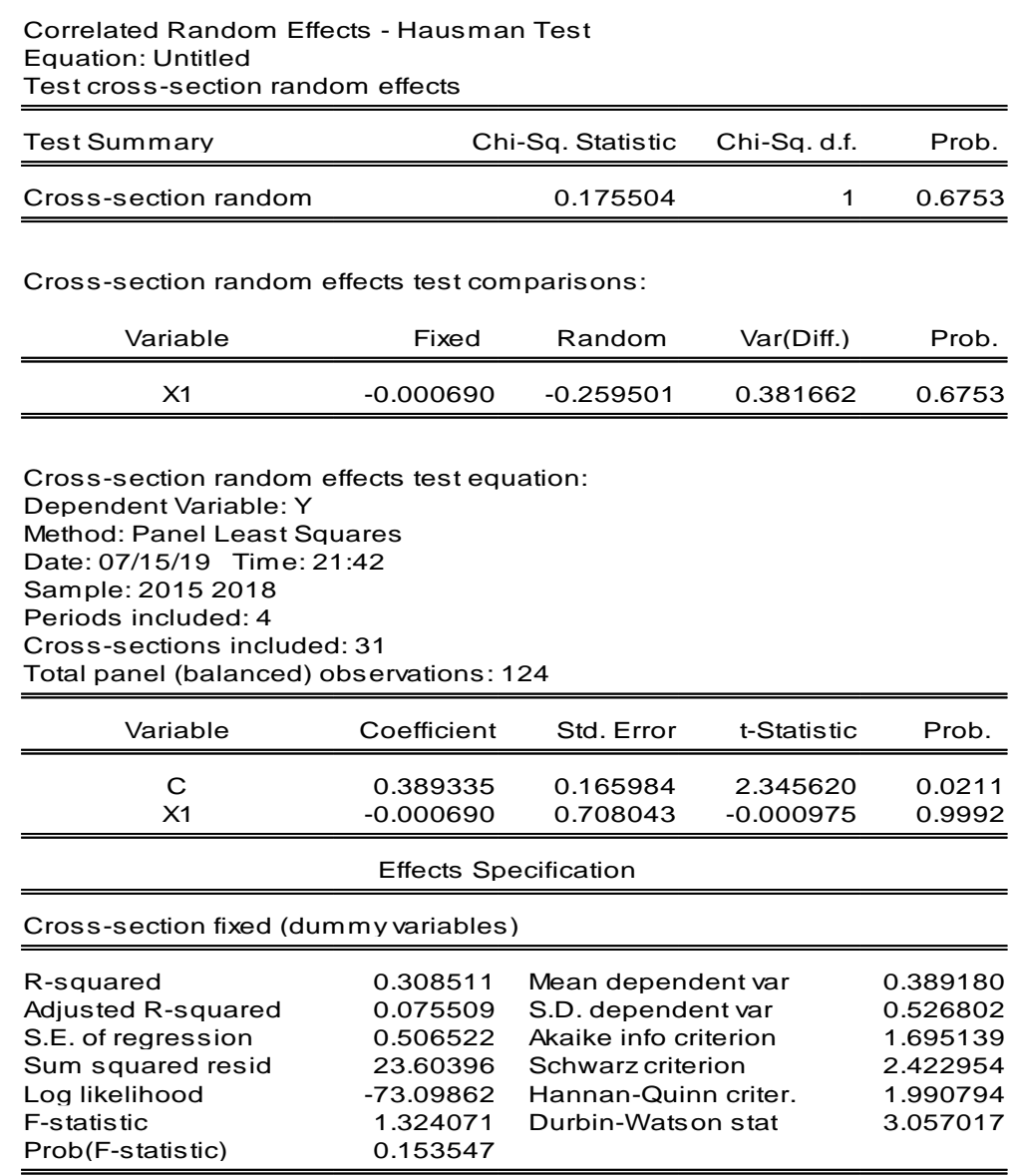

Sumber : Hasil olah data e-views 9, 2019.

Hasil Uji Hausman pada tabel di atas menunjukkan nilai probabilitas cross section adalah $0.6753>0.05$, maka terima $\mathrm{H}_{0}$, yang berarti pada tingkat signifikansi 5\% maka lebih efektif menggunakan pendekatan Random Effect Model dibandingkan Fixed Effect Model.

\section{Uji Asumsi Klasik}

\section{Uji Normalitas}

Uji normalitas merupakan pengujian terhadap kenormalan distribusi data. Jika suatu residual model tidak terdistribusi normal, maka uji t kurang relevan digunakan untuk menguji koefisien regresi. Pengujian normalitas pada penelitian ini akan dilakukan dengan menggunakan Jarque-Bera. Probability menunjukkan kemungkinan nilai Jarque-Bera melebihi nilai terobservasi di bawah hipotesis nol. Jika probability lebih besar dari nilai signifikansi, maka data terdistribusi normal. 


\section{Tabel 5. Uji Normalitas}

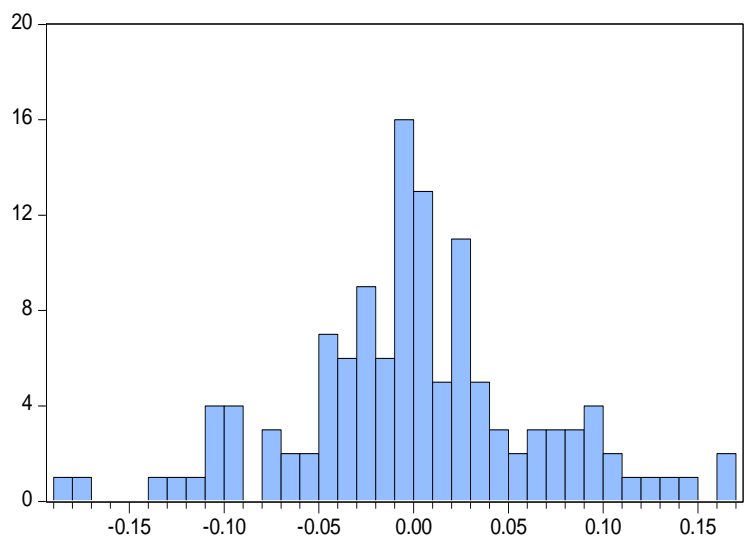

\begin{tabular}{lc}
\hline Series: Standardized Residuals \\
Sample 2015 2018 \\
Observations & 124 \\
& \\
Mean & $2.63 \mathrm{e}-18$ \\
Median & -0.000857 \\
Maximum & 0.166730 \\
Minimum & -0.182466 \\
Std. Dev. & 0.063881 \\
Skewness & -0.011430 \\
Kurtosis & 3.525281 \\
& \\
Jarque-Bera & 1.428287 \\
Probability & 0.489611 \\
\hline
\end{tabular}

Sumber : Hasil olah data eviews 9, 2019.

Berdasarkan tabel 4.4 di atas, nilai probability dari Jarque-Bera menunjukkan angka 0.489611 yang berarti lebih besar dari tingkat signifikansi sebesar 0.05 , sehingga dapat dikatakan data terdistribusi normal

\section{Uji Non Autokorelasi}

Menurut Santoso (2012), uji autokorelasi digunakan untuk mengetahui apakah dalam sebuah model regresi linier ada korelasi antara kesalahan penganggu pada periode $\mathrm{t}$ dengan $\mathrm{t}-1$ atau peridode sebelumnya.

\section{Tabel 6. Uji Non Autokorelasi}

\begin{tabular}{|c|c|c|c|c|}
\hline \multicolumn{5}{|c|}{$\begin{array}{l}\text { Dependent Variable: Y } \\
\text { Method: Panel EGLS (Cross-section random effects) } \\
\text { Date: } 07 / 15 / 19 \text { Time: } 22: 15 \\
\text { Sample: } 20152018 \\
\text { Periods included: } 4 \\
\text { Cross-sections included: } 31 \\
\text { Total panel (balanced) observations: } 124 \\
\text { Swamy and Arora estimator of component variances } \\
\end{array}$} \\
\hline Variable & Coefficient & Std. Error & t-Statistic & Prob. \\
\hline $\begin{array}{l}\times 1 \\
\mathrm{Z} \\
\mathrm{C}\end{array}$ & $\begin{array}{r}-0.257952 \\
-0.639734 \\
0.508744\end{array}$ & $\begin{array}{l}0.328156 \\
0.344338 \\
0.094717\end{array}$ & $\begin{array}{r}-0.786064 \\
-1.857866 \\
5.371220\end{array}$ & $\begin{array}{l}0.4334 \\
0.0656 \\
0.0000\end{array}$ \\
\hline \multicolumn{5}{|c|}{ Effects Specification } \\
\hline $\begin{array}{l}\text { Cross-section random } \\
\text { Idiosyncratic random }\end{array}$ & & & $\begin{array}{l}0.111962 \\
0.508135\end{array}$ & $\begin{array}{l}0.0463 \\
0.9537\end{array}$ \\
\hline \multicolumn{5}{|c|}{ Weighted Statistics } \\
\hline $\begin{array}{l}\text { R-squared } \\
\text { Adjusted R-squared } \\
\text { S.E. of regression } \\
\text { F-statistic } \\
\text { Prob(F-statistic) }\end{array}$ & $\begin{array}{l}0.032805 \\
0.016818 \\
0.509081 \\
2.052028 \\
0.132922\end{array}$ & \multicolumn{2}{|c|}{$\begin{array}{l}\text { Mean dependent var } \\
\text { S.D. dependent var } \\
\text { Sum squared resid } \\
\text { Durbin-Watson stat }\end{array}$} & $\begin{array}{l}0.356133 \\
0.513417 \\
31.35883 \\
2.295903\end{array}$ \\
\hline \multicolumn{5}{|c|}{ Unweighted Statistics } \\
\hline $\begin{array}{l}\text { R-squared } \\
\text { Sum squared resid }\end{array}$ & $\begin{array}{l}0.038044 \\
32.83635\end{array}$ & $\begin{array}{l}\text { Mean deper } \\
\text { Durbin-Wats }\end{array}$ & $\begin{array}{l}\text { ent var } \\
\text { n stat }\end{array}$ & $\begin{array}{l}0.389180 \\
2.192595\end{array}$ \\
\hline
\end{tabular}

Sumber : Hasil olah data e-views 9, 2019 
Tabel 4.5 menunjukkan nilai Durbin-Watson sebesar 2.192595. Nilai ini akan dibandingkan dengan nilai tabel dengan menggunakan signifikansi $5 \%$. Untuk jumlah sample $(\mathrm{n})=124$, dan $\mathrm{k}=3$, nilai $\mathrm{dL}=1.613$ dan $\mathrm{du}=1.736$. Oleh karena nilai DW $1.736<2.192<2.264$ (4-1.736), maka dapat disimpulkan tidak terjadi autokorelasi.

\section{Uji Non Heterokedatisitas}

Uji non heterokedastisitas digunakan untuk melihat apakah residual dari model yang terbentuk memiliki varians yang konstan atau tidak. Dengan adanya heterokedastisitas, uji t dan uji f menjadi tidak akurat (Santoso, 2012).

\section{Tabel 7. Uji Non Heterokedastisitas}

\begin{tabular}{|c|c|c|c|c|}
\hline \multicolumn{5}{|c|}{ Heteroskedasticity Test: Breusch-Pagan-Godfrey } \\
\hline $\begin{array}{l}\text { F-statistic } \\
\text { Obs* R-squared } \\
\text { Scaled explained SS }\end{array}$ & $\begin{array}{l}1.422099 \\
2.847775 \\
53.52245\end{array}$ & $\begin{array}{l}\text { Prob. } \mathrm{F}(2,12 \\
\text { Prob. Chi-Sc } \\
\text { Prob. Chi-Sc }\end{array}$ & $\begin{array}{l}\text { are(2) } \\
\text { are }(2)\end{array}$ & $\begin{array}{l}0.2452 \\
0.2408 \\
0.0000\end{array}$ \\
\hline \multicolumn{5}{|c|}{$\begin{array}{l}\text { Test Equation: } \\
\text { Dependent Variable: RESID^2 } \\
\text { Method: Least Squares } \\
\text { Date: } 07 / 15 / 19 \text { Time: } 23: 00 \\
\text { Sample: } 1124 \\
\text { Included observations: } 124\end{array}$} \\
\hline Variable & Coefficient & Std. Error & $\mathrm{t}$-Statistic & Prob. \\
\hline $\begin{array}{l}\mathrm{C} \\
\mathrm{X} 1 \\
\mathrm{Z}\end{array}$ & $\begin{array}{r}0.678245 \\
-1.408680 \\
-0.998916 \\
\end{array}$ & $\begin{array}{l}0.289480 \\
1.001141 \\
1.089393\end{array}$ & $\begin{array}{r}2.342974 \\
-1.407075 \\
-0.916948 \\
\end{array}$ & $\begin{array}{l}0.0208 \\
0.1620 \\
0.3610\end{array}$ \\
\hline $\begin{array}{l}\text { R-squared } \\
\text { Adjusted R-squared } \\
\text { S.E. of regression } \\
\text { Sum squared resid } \\
\text { Log likelihood } \\
\text { F-statistic } \\
\text { Prob(F-statistic) }\end{array}$ & $\begin{array}{r}0.022966 \\
0.006817 \\
1.664586 \\
335.2723 \\
-237.6174 \\
1.422099 \\
0.245210\end{array}$ & \multicolumn{2}{|c|}{$\begin{array}{l}\text { Mean dependent var } \\
\text { S.D. dependent var } \\
\text { Akaike info criterion } \\
\text { Schwarz criterion } \\
\text { Hannan-Quinn criter. } \\
\text { Durbin-Watson stat }\end{array}$} & $\begin{array}{l}0.264769 \\
1.670288 \\
3.880926 \\
3.949158 \\
3.908643 \\
1.958369\end{array}$ \\
\hline
\end{tabular}

Sumber : Hasil olah data eviews 9, 2019

Tabel 4.6 menunjukkan nilai Prob. Chi-square (2) pada Obs-R-Squared yaitu sebesar 0.2408 . Oleh karena nilai probabily $0.2408>0.05$, maka model regresi tidak ada masalah heterokedastisitas.

\section{Uji Kelayakan Model}

\section{Uji Hipotesis}

Uji hipotesis berguna untuk menguji signifikansi kerfisien regresi yang didapat. Pengambilan keputusan hipotesis dapat dilakukan dengan membandingkan $\mathrm{t}$ statistik dengan $\mathrm{t}$ tabel atau nilai probabilitas terhadap taraf signifikansi yang ditetapkan penulis. 


\section{Tabel 8. Uji Regresi Moderating}

\begin{tabular}{|c|c|c|c|c|}
\hline \multicolumn{5}{|c|}{$\begin{array}{l}\text { Dependent Variable: Y } \\
\text { Method: Panel EGLS (Cross-section random effects) } \\
\text { Date: } 07 / 23 / 19 \text { Time: } 22: 05 \\
\text { Sample: } 20152018 \\
\text { Periods included: } 4 \\
\text { Cross-sections included: } 31 \\
\text { Total panel (balanced) observations: } 124 \\
\text { Swamy and Arora estimator of component variances }\end{array}$} \\
\hline Variable & Coefficient & Std. Error & $\mathrm{t}$-Statis tic & Prob. \\
\hline $\begin{array}{l}X 1 \\
X 1 * Z \\
C\end{array}$ & $\begin{array}{r}0.568507 \\
0.142317 \\
-1.182602 \\
\end{array}$ & $\begin{array}{l}0.184410 \\
0.039437 \\
0.306303\end{array}$ & $\begin{array}{r}3.082836 \\
3.608730 \\
-3.860887 \\
\end{array}$ & $\begin{array}{l}0.0025 \\
0.0004 \\
0.0002\end{array}$ \\
\hline \multicolumn{5}{|c|}{ Effects Specification } \\
\hline $\begin{array}{l}\text { Cross-section rando } \\
\text { ldiosyncratic random }\end{array}$ & & & $\begin{array}{l}0.659846 \\
0.940714\end{array}$ & $\begin{array}{l}0.3298 \\
0.6702\end{array}$ \\
\hline \multicolumn{5}{|c|}{ Weighted Statistics } \\
\hline $\begin{array}{l}\text { R-squared } \\
\text { Adjusted R-squared } \\
\text { S.E. of regression } \\
\text { F-statistic } \\
\text { Prob(F-statistic) } \\
\end{array}$ & $\begin{array}{l}0.107644 \\
0.092894 \\
0.942814 \\
7.298054 \\
0.001018 \\
\end{array}$ & \multicolumn{2}{|c|}{$\begin{array}{l}\text { Mean dependent var } \\
\text { S.D. dependent var } \\
\text { Sum squared resid } \\
\text { Durbin-Watson stat }\end{array}$} & $\begin{array}{r}-0.809792 \\
0.989913 \\
107.5567 \\
1.363184\end{array}$ \\
\hline \multicolumn{5}{|c|}{ Unweighted Statistics } \\
\hline $\begin{array}{l}\text { R-squared } \\
\text { Sum squared resid }\end{array}$ & $\begin{array}{l}0.146693 \\
159.1283\end{array}$ & \multicolumn{2}{|c|}{$\begin{array}{l}\text { Mean dependent var } \\
\text { Durbin-Watson stat }\end{array}$} & $\begin{array}{r}-1.395106 \\
0.921392\end{array}$ \\
\hline
\end{tabular}

Sumber : Hasil olah data eviews 9, 2019

Dari tabel di atas terlihat bahwa Corporate Social Responsibility berpengaruh terhadap penghindaran pajak dengan nilai prob sebesar 0.0025 . Hal ini berarti menolak $\mathrm{H}_{0}$. Hal ini berarti semakin luas pengungkapan CSR maka semakin tinggi praktik penghindaran pajak yang dilakukan oleh perusahaan. Hal ini menunjukkan bahwa praktik pengungkapan tanggung jawab sosial membutuhkan biaya yang tidak sedikit, sehingga perusahaan akan melakukan alokasi antara biaya-biaya yang akan dikeluarkan terkait aktivitas CSR dan pembayaran pajak. Praktik penghindaran pajak yang dilakukan adalah dengan membebankan biaya CSR sebagai pengurang penghasilan bruto, sehingga laba menjadi lebih kecil. Perusahaan dengan pengungkapan CSR yang sempit, dapat melakukan penghindaran pajak dengan memperbesar biaya CSR. Hal ini sejalan dengan penelitian yang dilakukan oleh Elisa Tjondro (2016), Lanis (2011), dan Davis (2015) yang mengungkapkan bahwa Corporate Social Responsibility berpengaruh terhadap Penghindaran Pajak.

Hasil pengujian terhadap peran kinerja laba dalam memoderasi pengaruh antara Corporate Social Responsibility terhadap Penghindaran Pajak menunjukkan bahwa kinerja laba memoderasi pengaruh CSR terhadap Penghindaran Pajak. Hasil pengujian menunjukkan variabel efek moderasi memiliki nilai probability sebesar 0.0004 atau lebih kecil dari 0.05 dengan nilai tstatistik menunjukkan angka positif, artinya tolak $\mathrm{H}_{0}$ yang berarti Kinerja Laba mampu memperkuat pengaruh antara Corporate Social Responsibility terhadap Penghindaran Pajak. Hal tersebut menunjukkan bahwa interaksi kinerja laba dengan luasnya pengungkapan CSR memperkuat pengaruh terhadap penghindaran 
pajak. Ini berarti, semakin luas pengungkapan CSR dan semakin tinggi laba yang dihasilkan perusahaan, maka semakin tinggi pula praktik penghindaran pajak yang dilakukan oleh perusahaan. Perusahaan cenderung akan melakukan penghindaran pajak, ketika kinerja laba sedang tinggi dan di sisi lain perusahaan harus mengeluarkan biaya untuk aktivitas CSR. Hal ini sejalan dengan penelitian yang dilakukan oleh Elisa Tjondro (2016), yang menyatakan bahwa kinerja laba mampu memperkuat hubungan antara kualitas CSR terhadap penghindaran pajak. Namun penelitian Dewita Puspawati (2017) menunjukkan hasil sebaliknya, dimana kinerja laba memperlemah hubungan antara CSR terhadap penghindaran pajak.

\section{KESIMPULAN}

Berdasarkan hasil pengujian hipotesis, penelitian ini menunjukkan bahwa variabel Corporate Social Responsibility berpengaruh terhadap Penghindaran Pajak dan variabel kinerja laba mampu memperkuat hubungan antara pengaruh Corporate Social Responsibility terhadap Penghindaran Pajak.

Penelitian ini memiliki beberapa keterbatasan di antaranya adalah (1) jumlah sample hanya 124 sample, peneliti selanjutnya diharapkan menambah jumlah sample dengan memperpanjang periode penelitian, (2) penelitian ini menggunakan sample perusahaan multinasional sektor perkebunan, untuk peneliti selanjutnya diharapkan memperluas objek penelitian dengan mengambil sample yang lebih sensitif terhadap isu-isu perpajakan dan CSR.

\section{DAFTAR PUSTAKA}

Andriyanto, R., Effriyanti, E., \& Hidayat, A. (2018), The Effect of Spiritual Intelligence (SQ) and Personality Types on Auditor's Ability to Detect Fraud. JABI (Jurnal Akuntansi Berkelanjutan Indonesia), 1(3), 258-268.

Belkaoui, A. (1993) Accounting Theory (Terjemahan) Edisi ke 2, Jakarta, Erlangga.

Davis, A. K., D. A. Guenther, L. K. Krull, dan B. M. Williams (2016), Do Socially Responsible Firms Pay More Taxes?, The Accounting Review, Vol. 91. No. 1, 47-68.

Dewita (2018), Penghindaran Pajak dan CSR: Kinerja Laba sebagai Variabel Moderasi, University Research Colloquium, UMS.

Elisa, Tjondro (2016), Kualitas CSR dan Penghindaran Pajak dengan Kinerja Laba sebagai Moderator, Jurnal Akuntansi dan Keuangan, Vol. 18, No. 2, 105-118.

Hadi, Nur. (2011), Corporate Social Responsibility. Yogyakarta : Graha Ilmu

Hidayat, A., \& Sadewa, P. (2020), Pengaruh Penggunaan Aplikasi Eviews Terhadap Sikap Belajar dan Kemampuan Pemecahan Masalah Statistik. Edumaspul: Jurnal Pendidikan, 4(1), 321-328. 
Hutagaol, John. (2007), Perpajakan Isu-isu Kontemporer, Jakarta, Graha Ilmu

Lanis, R. dan G. Richardson. (2012), Corporate Social Responsibility and Tax Agressiveness: An Empirical Analysis. Journal of Accounting and Public Policy, Vol.31, No. 1, 86-108.

Republik Indonesia. (2007), Undang-Undang No. 40 Tahun 2007 Tentang Perseroan Terbatas, Lembaran Negara Republik Indonesia Tahun 2007 No 106.

Robins, S dan Coulter, M. (2007), Manajemen. Edisi Kedelapan. Jakarta, PT Indeks

Santoso, Singgih. (2012), Panduan Lengkap SPSS Versi 20, Jakarta, PT Elex Media Komputindo

Watson, L. (2014), Corporate Social Responsibility, Tax Avoidance and Earning Performance. The Journal of the American Taxation Association (JATA), Vol. 37, No. 2, 1-21 